\title{
Is A Problem Shared, A Problem Halved? Not Always! The Novel Coronavirus COVID-19 Outbreak
}

\author{
Shilpushp Bhosale ${ }^{1}$, Atul P Kulkarni ${ }^{2}$ \\ Indian Journal of Critical Care Medicine (2020): 10.5005/jp-journals-10071-23365
}

The global health crisis caused by the novel coronavirus-2019 [nCoV (SARS-CoV-2, now renamed as COVID-19)] outbreak has involved, since December 2019 [71,429 confirmed cases (70,635 in China alone)]. ${ }^{1}$ The number of additional people getting affected is rising with people traveling to different continents by sea and air, infection now enveloping all continents. This obviously increases the health and economic burden of all affected countries. The International Monetary Fund (IMF) Managing Director Kristalina Georgieva predicted a damage to global growth due to this epidemic. There have been more than 2000 deaths in China, with 4 more occurring in other countries (Hong Kong, the Philippines, Japan and France). In Kerala, three students tested positive, but the viral spread in India seems to be contained as of now.

Coronaviruses, enveloped viruses with distinct "club-like" projections by the spike (S) protein-forming crown, were supposed to cause benign illness such as common cold. ${ }^{2}$ All human CoVs are zoonotic with bats being the key reservoir. ${ }^{3}$ Over the last two decades, however, they have caused outbreaks of severe respiratory illnesses in humans such as the severe acute respiratory syndrome (SARS) epidemic (2002 SARS) and 2012 Middle East Respiratory Syndrome (MERS)-CoV epidemic, with high morbidity and mortality. The intermediate hosts in these epidemics were palm civets and dromedary camels, respectively. ${ }^{4}$ The $\mathrm{nCoV}$ detected in China is genetically closely related to the 2002 SARS virus, but the exact origin of the COVID-19 is still not understood. ${ }^{5}$ It is speculated that the disease may have originated from the Wuhan seafood market, and the peak travel season due to the Chinese New Year may have been a important factor that led to the global spread of the infection.

The 2002 SARS epidemic affected more than 8,000 people [794 deaths with case fatality ratio (CFR) 10\%], while the CFR of MERS-CoV infections was estimated at 35\% with more than 2,200 infected. ${ }^{6,7}$ It is difficult to estimate CFR for COVID-19 since data are still emerging, but preliminary estimates of CFR are in the range of $11-14 \% .^{8}$ The Center for Disease Control and Prevention (CDC) in China estimates an incubation period range of 3-7 days, with a maximum of 14 days, this means the quarantine period of 2-4 weeks. Unlike SARS, COVID-19 seems to affect young and the elderly with comorbidities such as diabetes, pregnancy, immunosuppressed, and immunocompromised patients. The World Health Organization (WHO) has published CoV disease's (COVID-19) technical guidance on its website. ${ }^{9}$

\section{Infection Control and Public Health Measures}

It is important to make a clear distinction between suspect and contacts, so that suspects can be tracked, isolated, and treated
1,2Division of Critical Care Medicine, Department of Anaesthesiology, Tata Memorial Centre, Homi Bhabha National Institute, Mumbai, Maharashtra, India

Corresponding Author: Atul P Kulkarni, Division of Critical Care Medicine, Department of Anaesthesiology, Tata Memorial Centre, Homi Bhabha National Institute, Mumbai, Maharashtra, India, Phone: +91 9869077526, e-mail: kaivalyaak@yahoo.co.in

How to cite this article: Bhosale S, Kulkarni AP. Is A Problem Shared, A Problem Halved? Not Always! The Novel Coronavirus COVID-19 Outbreak. Indian J Crit Care Med 2020;24(2):88-89.

Source of support: Nil

Conflict of interest: None

as soon as possible, while the contacts can be quarantined for at least 2-4 weeks. Measures for large-scale public awareness regarding the standard recommendations to prevent infection spread include regular handwashing; covering mouth and nose when coughing and sneezing; thoroughly cooking meat and eggs; avoiding close contact with anyone showing symptoms of respiratory illness such as coughing and sneezing; and avoiding touching eyes, nose, and mouth. Previous experience from the SARS-CoV and MERS-CoV outbreaks suggests that hospitals and healthcare facilities have amplified disease spread; hence, there has to be a special emphasis on higher level measures such as healthcare preparedness, large-scale isolation facilities, and quarantine facilities. The CDC and the WHO guidelines suggest that stringent infection control measures are critical to preventing transmission to healthcare workers and other patients. Standard measures such as hand hygiene and use of chlorhexidine with $70 \%$ isopropyl alcohol for hand rub, use of personal protective equipment with triple layer mask or N95 mask, along with education regarding proper disposal of the these equipment should be instituted in healthcare facilities. Since the virus stays on surfaces, efficient surface cleaning with standard $1 \%$ hypochlorite solution is recommended. Standard droplet precautions (e.g., surgical or procedure mask, gown, and gloves) are indicated during the treatment of all CoV patients, and such protocols for dropletspread respiratory viruses should be part of hospital infection control practices. Additional respiratory precautions are needed during aerosol-generating procedures.

\section{How Prepared are We in India?}

India has so far reported three confirmed cases of nCoV from Kerala. These were medical students studying at the Wuhan University. Meanwhile, all the 645 Indian nationals who were

() The Author(s). 2020 Open Access This article is distributed under the terms of the Creative Commons Attribution 4.0 International License (https://creativecommons. org/licenses/by-nc/4.0/), which permits unrestricted use, distribution, and non-commercial reproduction in any medium, provided you give appropriate credit to the original author(s) and the source, provide a link to the Creative Commons license, and indicate if changes were made. The Creative Commons Public Domain Dedication waiver (http://creativecommons.org/publicdomain/zero/1.0/) applies to the data made available in this article, unless otherwise stated. 


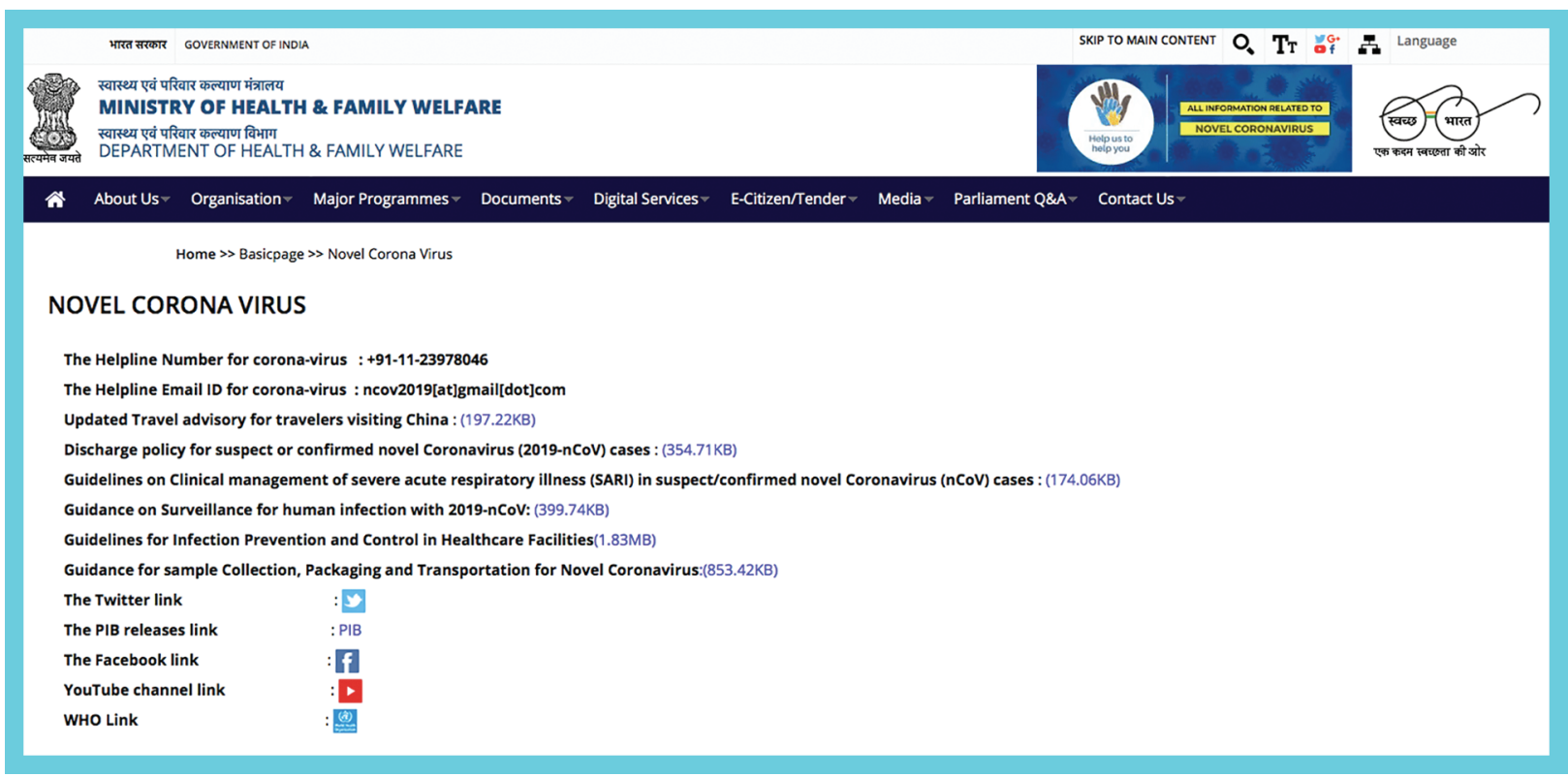

Fig. 1: Ministry of Health and Family Welfare: Helpline and other information for nCOVID-19 virus

evacuated from Wuhan tested negative for infection. The Indian Government has to set up a task force to monitor the situation arising out of the $\mathrm{nCoV}$, with representatives from the Ministries of Health, Home, Civil Aviation, and Women and Child Development. A round-the-clock control room at the Directorate General of Health Services' headquarters is set up to address queries related to the virus. The Ministry of Health and Family Welfare website displays the information and notices related to the novel COVID-19 outbreak, which is of help to the travelers and health professionals along with contact details (Fig. 1). ${ }^{10}$ The Government of India is closely monitoring the development of $\mathrm{nCoV}$ while providing isolation, testing, and quarantine facilities. The Government of India has issued an advisory for Indian citizens not to travel to China.

\section{The Way Forward}

Human history is replete with multiple examples of our fight with nature, while losing ground for some time, after a large number of fatalities, we have triumphed so far against the microorganisms. The best way to protect the noninfected population is vaccination. We have come a long way since Edward Jenner developed the first vaccine against smallpox (1796), employing what appears to be a very crude method now. The human genome project mapped complete genome sequence, a milestone in human history (April 14, 2001). This has prepared us for future challenges. Codagenics, a USA firm, and Serum Institute of India, have entered into a partnership, to rapidly codevelop a vaccine for COVID-19. ${ }^{11}$ Many such efforts are ongoing and it is estimated that the vaccine will be available within the next 6 months, signaling another triumphal milestone in human history.

\section{References}

1. https://www.who.int/docs/default-source/coronaviruse/situationreports/20200217-sitrep-28-covid-19.pdf, last accessed on 18th Feb 2020.

2. Kolesnikova L, Slenczka W, Brodt H, Klenk H, Becker S. Electron microscopy in diagnostics of SARS case. Microsc Microanal 2003;9(S03):438-439. DOI: 10.1017/S1431927603035104.

3. Brook CE, Dobson AP. Bats as 'special' reservoirs for emerging zoonotic pathogens. Trends Microbiol 2015;23(3):172-180. DOI: 10.1016/j.tim.2014.12.004.

4. Corman VM, Muth D, Niemeyer D, Drosten C. Hosts and sources of endemic human Coronaviruses. Adv Virus Res 2018;100:163-188. DOI: 10.1016/bs.aivir.2018.01.001.

5. Hu D, Zhu C, Ai L, He T, Wang Y, Ye F, et al. Genomic characterization and infectivity of a novel SARS-like coronavirus in chinese bats. Emerg Microbes Infect 2018;7(1):154. DOI: 10.1038/s41426-018-0155-5.

6. Summary of probably SARS cases with onset of illness from 1 November 2002 to 31 July 2003. Geneva: World Health Organization. www.who.int/csr/sars/country/table2004_04_21/en/Last, accessed February 18th 2020.

7. Kim KH, Tandi TE, Choi JW, Moon JM, Kim MS. Middle East Respiratory Syndrome Coronavirus (MERS-CoV) Outbreak in South Korea, 2015: epidemiology, characteristics and public health implications. J Hosp Infect 2017;95(2):207-213. DOI: 10.1016/j.jhin.2016.10.008.

8. Huang C, Wang Y, Li X, et al. Clinical features of patients infected with 2019 novel coronavirus in Wuhan, vol. 20, China: Lancet; 2020. pp. 30183-30185, published online Jan 24. https://doi.org/10.1016/ S0140-6736.

9. https://www.who.int/emergencies/diseases/novel-coronavirus-2019/ technical-guidance/,. last accessed on 18th February 2020.

10. https://mohfw.gov.in/node/4904/last, accessed on 18th February 2020.

11. https://www.thepharmaletter.com/article/us-indian-collaborationon-vaccine-against-covid-19/last, accessed on 18th February 2020. 